\title{
BLURRING BOUNDARIES: HOW WRITING SLASH FANFICTION EMPOWERS YOUNG WOMEN IN MAINLAND CHINA
}

\author{
YIJIE COCO FANG
}

\begin{abstract}
This study pays close attention to Chinese slash fanfiction amateur female writers and their writing experiences. This research investigates in what kind of ways their writing experiences relate to a sense of female empowerment. The analysis emphasizes how slash writing as a seemingly individual and private experience connects itself to a larger community of writers and readers, and how this practice extends to the lived realities of gender and sexuality in mainland China. Using qualitative data from epistolary interviews with ten Chinese female slash writers, this study argues that writing slash fanfiction in mainland China is a boundary-blurring art. Through crossing and obscuring boundaries between private and public, fantasies and reality, individual and community, Chinese female slash writers retrieve a sense of agency and empowerment in their experiences of writing slash fanfiction through exploring affective experiences, reconciling with sexual fantasies, and serving and participating in a female community.
\end{abstract}

$\mathrm{F}$ anfiction refers to fictional pieces written by fans of prominent cultural products, featuring characters from books, TV series, movies, and variety shows, whose production and consumption activities usually take place within fan communities (Jenkins, 1992; Cumberland, 2003; Kalinowski, 2014; Gao, 2020; Taylor, 2020). Slash fanfiction is a subgenre in the fanfiction community that centers on love stories between two male characters, weaving together emotional arcs as well as pornographic plots (Russ, 1985; Jenkins, 1992; Cumberland, 2003). Far from being a literary product of self-pleasure, slash fanfiction aggressively addresses gender and sexuality, even with an attempt to remap traditional gender lines and norms (Russ, 1985; Lamb \& Veith, 1986; Cicioni, 1998; Boyd, 2001). The emancipatory part of slash writing has initiated many scholarly discussions of power and subversion, especially within the fields of gender and sexuality studies; however, few have directed their analyses towards the development of female slash fanfiction writing in mainland China, where homo-romantic/erotic fictions confront much stricter censorship; where homosexuality is still a sensitive and highly marginalized issue; and where women in public spheres talk about sex with much more reserve than men. Women writing slash fiction thereby constitutes a more taboo subject in mainland China, due to the multilayered subversion that is freely imagining courtship and eroticism between two males with a cross-gender and cross-sexuality perspective, and as a way to reconfigure erotic needs that goes against the grain of dominant culture. 


\section{Columbia Undergraduate Research Journal}

Given this context, this study pays close attention to Chinese slash fanfiction amateur female writers and their writing experiences. This research investigates the ways that women's writing experiences relate to a sense of female empowerment. The analysis that follows emphasizes how slash writing as a seemingly individual and private experience connects to a larger community, and how this practice extends to the contemporary gendered realities of mainland China. To answer my research question, the present study reviews both Western and Chinese literature on femaledominated online fandoms, gender dimensions of slash, and the subtle relationship between slash consumption and slash communities. Then, using qualitative data from ten epistolary interviews, this study argues that writing slash fanfiction in mainland China is a boundary-blurring art. Through crossing and obscuring boundaries between private and public, fantasies and reality, individual and community, Chinese female slash writers retrieve a sense of agency and empowerment in their experiences of writing slash. Here, "blurring" connotes a dual meaning: to speak something communal in individual manners and to extend individual feelings to a larger community. The way in which female slash writers handle emotions, erotica, and postwriting activities in their writing experiences becomes the source of their agency and empowerment.

\section{Women in the World of Online Fanfiction}

Fanfiction exists within the framework of fandom and fan communities. Early systematic studies on fan communities date back to Henry Jenkins' book Textual Poachers: Television Fans and Participatory Culture, where he analyzes offline social interactions in fanzines and refers to this group interaction as a source of collective identity building (Jenkins, 1992). However, the last twenty years have witnessed the ubiquity of Internet access which has dramatically changed modes of interaction among fan communities.

With the increased availability of the Internet, women have become much more active in producing, circulating, and consuming fanfiction under the protection of cyberspace. Cumberland (2003) and Kalinowski (2014) both stress the dominant participation of women in online fan communities; in parallel with these Western findings, Gao (2020) also notices that in mainland China female-oriented cyberspace and cultural production are taking over the field of popular culture. By inquiring into women's ruling status in online fandom, these studies also situate the massive production and ever-growing popularity of fanfiction in the participatory culture of the digital world. The openness and anonymity of cyberspace allow women to compose and discuss fanfiction with much more flexibility, enabling them to explore gender and sexuality themes in a community of like-minded female participants (Cumberland, 2003; Kalinowski, 2014). In addition, since many fan texts involve a fair amount of erotica, the Internet fanfiction world provides women writing them with a 


\section{Columbia Undergraduate Research Journal}

safe place, where they can freely experiment with and challenge traditional gender roles in fanfiction texts (Cumberland, 2003; Gao, 2020). Women's use of cyberspace has made fan websites into women-only clubs.

\section{Gendered Dimensions of Slash: How is Slash Empowering?}

\section{What is Slash?}

Slash is one of the subgenres of fanfiction. Today, slash has become the mainstream of adult fanfiction on the Internet (Cumberland, 2003; Gao, 2020). However, slash does not have a unanimous definition in the scholarly literature that captures all its characteristics. Early scholars such as Russ (1985) and Lamb and Veith (1986) took a feminist approach to interpret slash fanfiction as only about sexual fantasies by women for women. Following this analytic path, Cicioni (1998) defines slash writings as "women's active reconstruction of representations of male pairbonds" (p.153). Busse and Helleskon (2006) articulate slash's engagement with homoeroticism by focusing on fan authorship and readership, defining slash as stories that "posit a same-sex relationship imposed by the author" based on "perceived homoerotic subtexts" (p.10). Cumberland (2003) reiterates its overlaps with erotica but offers a more restricted definition that bounds its writers and audiences only within heterosexual women. As different as each interpretation may seem, scholars have approached its definition from three main aspects: fandom (its dependence on fan communities), gender (its appeal to women), and homoeroticism (its focus on malemale relationships). Building upon this ongoing conversation, I propose in this paper a working classification system for slash that addresses the above three themes:

1. It is a subgenre of fanfiction, thus incorporating all the features of fanfiction discussed above.

2. It refers specifically to male/male pairings in the content.

3. Its authors and audiences are primarily composed of women.

4. Each slash text engages in a different level of homoeroticism, from depictions of pure romances to "porn without plots" between male protagonists.

\section{To What Extent is Slash "Subversive"?}

The history of fanfiction studies is, as Busse and Helleskon (2006) summarize, a history of "attempting to understand the underlying motivations of why (mostly) women write fan fiction and, in particular, slash" (p.17). Early studies that investigated the relationship between slash and female power adopted a feminist analytic framework to interpret the structures, language, and themes of popular slash texts. Scholars such as Russ (1985) and Lamb and Veith (1986) agree that slash represents a liberatory practice for the women writing it, since this practice counters a repressed notion of femininity that figures women as being passive and reticent in sexual activities. They view slash stories as a reservoir of overtly expressed sexual fantasies 


\section{Columbia Undergraduate Research Journal}

where women recognize and obtain a desired socio-erotic position, a position that they can never reach in a sexist culture (Russ, 1985; Lamb and Veith, 1986). The fact that the emancipatory dimension of slash is fulfilled by its sexual release through fantasy, to some extent, coincides with the conclusions of feminist analyses of the power of reading male-female romance fiction. According to Radway (1984) and Snitow (1983), reading romance offers women spaces for provisional transcendence in a sexist society as it "fill[s] a place left empty for most people" by taking women's fantasies seriously (Snitow, p.246), and provides an alternative means of channeling and expressing female sexual desires.

As such, slash as a literary genre sits at the intersection of pornography and romance; its gendered implications are also indebted to how women relate to both genres. However, slash is inherently different from traditional romance fiction because of its radical departure from standard romances, as manifest by its extended depictions of the male body/flesh as an object of desire, exaggerated versions of sexual intensity and arousal, and illustrations of an egalitarian love (Russ, 1985; Jenkins, 1992; Cicioni, 1998; Boyd, 2001; Jones, 2002). All these aspects point to women's attempts to transgress conventional gender norms.

But the answer to whether slash is truly subversive is more complex than that which meets the eye. Some scholars argue that slash reflects and reproduces differences and tensions between the sexes under the guise of its conspicuously subversive content. For example, a circuitous form of sexual expression is identified in slash texts (Russ, 1985; Jenkins, 1992). The lengthy depictions of waiting in slash texts, usually enriched by the male characters' endless hesitations and scruples, precisely reflect what society tells a woman to do before any sexual advances with men: to wait (Russ, 1985). Also, in female fantasy scenarios in slash, the egalitarian love constructed between two males, according to female slash fans in Cicioni's study (1998), is impossible between men and women. This tension reveals not only a prevailing unease about the institution of heterosexuality but also a deeply entrenched obsession with a monogamous partnership or marriage. Furthermore, akin to Snitow's analysis (1983) of Harlequin romance and its popularity among women, slash also exemplifies an inherent ambivalence toward reading romance: more than as a mere outlet for sexual release, romance may be the only "socially acceptable moment of transcendence" for women (p.252).

In short, slash on the one hand offers alternative forums for breaking traditional sexual values and gender norms and exploring the social construction of gender with greater openness, freedom, and self-awareness. On the other hand, it inevitably captures and reproduces the tensions and anxieties of women about gender and sexuality with regard to socially disciplined elements in their daily life. With its contested gendered dimensions, slash is a far more complex cultural phenomenon open to different interpretations. However, existing slash texts, in spite of rich content worthy of further exploration, are nevertheless a static object that cannot reflexively 


\section{Columbia Undergraduate Research Journal}

answer questions about how these multilayered female experiences are intertwined in slash. To address these inquiries, some slash scholars redirect their attention from texts to the audience: the slash fan community.

\section{A Bounded Community: Slash Fans, Readers, and Writers}

Most research on slash takes specific slash texts as their unit of analysis. This emphasis on text, however, disregards the fact that slash as a collective artifact cannot be fully explored without looking into who is popularizing it: the slash fans, including slash readers and writers. Research on slash fans looks mainly at slash reading and writing within this group and how these experiences are intertwined with their sexual fantasies, gender identification, and, more broadly, gender politics. These findings, however, were only based on informal personal correspondences with a limited number of slash writers, while the primary method was the textual analysis of selected passages of slash pieces. Another problem is that these studies tend to refer to slash fans as a homogenous group and fail to isolate slash writers from this huge community. How slash writers view these male characters is still a question left unexplored.

Recently, there have been studies that pay exclusive attention to slash writers. For example, Jung (2004) and Heiden (2016) both used autoethnography to situate the author as a fan writer and draw on their own fanfiction writings to make generalized claims about how writing slash fanfiction is implicated in the trend of female consciousness and liberation. However, its conclusions may be unrepresentative of the fan writers' community, because the researchers are academics who, compared to generic fan writers, are better equipped with knowledge and sensitivity about sexuality and gender discourses. It is worth noting that not all slash writings, along with slash writers themselves, are self-conscious about the ways they rescript current gender politics. Jenkins (1992) and Cicioni (1998) have observed that political commitments are not part of popular slash stories; instead, many slash writers avoid disclosing political orientations in their texts and focus exclusively on interpersonal relationships.

Given this review of the existing literature on slash, we see that much of the academic discourse has taken place via an analysis of slash texts with little concern for the perspectives of slash writers; even among scholarly conversations about slash writers, there is still a lack of systematic, empirical research on amateur female slash writers, and slash female writers in China are still an underrepresented group in the existing literature. This ignorance of the "author-end" participation in slash fails to acknowledge and identify how amateur slash writers may differ from published slash authors and fan readers in terms of their motivations to compose, their writing processes and practices, their rationales for writing slash, and how they connect their writing to their identified sociosexual positions. This paper aims to fill these gaps by focusing particularly on amateur slash female writers in mainland China and by adopting an interview-dominated research method. 


\section{Columbia Undergraduate Research Journal}

\section{Method}

This study uses epistolary interviews with female slash writers as the data collection method, because of the sensitive, retrospective nature of my study as well as the efficacy of this method in promoting shared construction of knowledge about a subcultural social group. The asynchronous nature of the epistolary interview method allows the respondent to select available interview times, and to consider questions and responses with more flexibility, so that the respondent may feel more comfortable when presented with inquiries regarding both personal biographical accounts and orientations on gender/sexuality issues.

Furthermore, the epistolary nature of such interviews is effective in producing thoughtful exchanges about a topical phenomenon, in which the interviewer and the respondent "have opportunities to consider, clarify and expand their meaning" asynchronously, and those exchanges can be enriched by the use of "textual affordances that are not available in speech" (Lupton, 2020), as opposed to face-toface interviews. That epistolary interviews are highly suitable for obtaining opinions can be seen in my pilot studies, where I published a blog with a tag of Super-Vocal (a TV show in mainland with a large female-based fan community and female-driven fan fictions) in Sina Microblog (a popular online media platform in mainland China), asking the question: "What does it mean to you to write fan fiction in China?" I received more than 60 replies within 48 hours, and many of them exceeded 100 Chinese characters (the word limit per comment is 140 characters) with wellarticulated reasons. Those self-revealing accounts, analogies, and metaphors may not be generated verbally during a synchronous interview, which usually progresses with language colloquiality and emotional spontaneity; instead, they are laborious selfreflections and self-disclosures rendered most compelling in a textual, even poetic way. Therefore, in my study, I believe that epistolary interviews were the best method for my qualitative data collection.

As for the sampling strategy, I focused on a specific TV show in China called Super-Vocal 1 and a mainland-based fanfiction website called Lofter. Super-Vocal 1 has a big female-driven fan base (almost 3 million fans follow its official fan community in Sina Microblog) and a huge production of fanfiction (17390 fanfictions found in Archive of Our Own, known as AO3, a popular fanfiction website for worldwide fans to post, read, and comment on fan works); Lofter is the most frequently used fanfiction website in mainland China because of its fandom development and readership adherence. Given Lofter's popularity in mainland slash fanfiction communities, I started sampling by first searching for the top 20 popular slash fanfiction writings on this website. Specific writers of those selected fanfiction pieces were located and approached. Finally, ten epistolary interviews were virtually conducted. 


\section{Columbia Undergraduate Research Journal}

As for the characteristics of the sample, all of the respondents are young women aged 18-29, mostly from provincial or coastal cities in mainland China, and some of them are from the international student community. Their sexual orientations are diverse: 6 are bisexual, 3 are heterosexual, and 1 is homosexual. In terms of marital status, 6 are single and 4 are in a relationship. The names of the respondents that appear as follows are all fictitious.

\section{Findings}

Writing slash is far more than personal preferences or female fantasies written onto male bodies; it is written by women for women, never with a consciousness of male readership. It should also not be reduced to pornography; erotic imagery is just one aspect of what a slash writer considers while composing a text. Writing slash is more like a female performance that truly speaks to women's issues: their anxieties, pleasures, private contemplations, networking, and opinions; it is a performance taking place in a highly inclusive women's community. Above all, it is women from diverse backgrounds animating a heterotopia uncontaminated by outside scrutiny, comment, and criticism. The way in which female slash writers handle emotions, erotics, and post-writing activities in their writing experiences constitute three main themes that emerged from the ten epistolary interviews.

\section{"Becoming Them"}

Slash writing provides women with various emotional and intimate possibilities to explore, through an act of remaking male characters in their writing experiences. The very premise of such experimentation with intimate relationships is that slash functions as a private shell that allows female slashers to temporarily hide from the endless demands of work, study, socializing, and family matters, a place where they have adequate personal space to carry out unconstrained explorations of various interpersonal relationships, especially intimate ones.

This exploration of the world of emotions confirms the idea that love is an eternal theme in slash. Many interviewees spoke of how, despite the fact that one of their own homoerotic stories focused on the romantic routines between two men, they still felt that the value of homoerotic stories was not in providing them with the opportunity to imagine intimate relationships that they could not covet in real life. Simply put, the value of the act of writing slash is not in fulfilling some fantasy, but in providing space for exploration. In most cases, respondents admitted that their actual emotional lives were not very rich. After creating homoerotic written works, their emotional trajectories begin to change: Rather than diverting some of their energy from maintaining various relationships in reality to project onto male characters, they tapped into their hearts for more forward-looking, retrospective and imaginative thinking about intimate relationships and thus expanded their emotional landscape. 


\section{Columbia Undergraduate Research Journal}

Here, this newly infused emotion flows between the author and the male characters, and one respondent Casey mentions that her emotions in her slash writings are often magnified: "I'm trying to lean into my love for them to counteract the pain that some relationships in reality have brought to me... I unknowingly embody 'yell at what's missing' when I write slash, and what I yell at most often is to love and be loved."

Vickie agrees with Casey that slashers' emotions are intensified both in the texts they create and in the action of creating: "Emotions that slash writers need to invest in their writings cannot be compared with readers'... We need to break ourselves to become them; I know that he is not me, but I have to be him." A slash writer has a deep and subtle emotional connection to her characters, but it is interesting to note that all of the respondents said they did not have sexual fantasies about any of their male protagonists similar to those female fans have about their male idols, even though they could have a crush on men in real life. Rather than actually "stepping into the shoes" of a male character and entering into an intimate relationship with another male protagonist from a female perspective, a female slash writer will first get to know the male characters she wants to remake, and act out their behavior based on her own thoughts about what he would do in a certain situation, what choices to make, and what comportment and emotional reactions to have. "The whole chain of logic of my slash stories is centered on him, not me, so I simply don't substitute myself into a certain male character," said Veronica. However, many interviewees also said that if such feelings of substitution are placed at the level of individual sensibilities, there must be the intervention of personal experiences in the story and characterization. In this case, the writer uses some personal and private thoughts about love to set up a hypothetical environment for the character.

The complication of substitution bespeaks an issue of otherness in writing slash - that is, female slashers retrieve a sense of agency in claiming a textual ownership of male identity and male comportment by activating romantic scenarios associated with their familiar male characters. Here, the boundaries between being a female self and being a male character are blurred, and in the path of "becoming them", female slashers take on and animate a male pose or a role open to anyone to express their situation and make their own situation expressible.

\section{Normalizing Erotica}

All the interviewees revealed a consensus: Writing erotica in slash is by all means "normal" because it functions almost to fulfill "individual pleasure," and women should not "feel ashamed of' writing about it. They have normalized, if not been proud of, erotica in the process of writing slash, and they recognize the pleasure and beauty this kind of erotica brings them. The process of writing homoeroticism is also a process of reconciliation with their own sexual expression and an interrogation of the repression of female desire. 


\section{Columbia Undergraduate Research Journal}

The sexual explicitness in slash, as argued by Russ (1985), is still a prominent feature in slash texts written in Chinese, manifested firstly in a large portion of depictions of male flesh. Contrary to traditional pornographic genres which rarely labor over the physical beauty of a male protagonist but over his clothes, facial expressions, behaviors and gestures that often function as an initiation of desire from the heroine (Radway, 1984), painstaking portrayals of male bodies abound in slash, where these bodies arouse sexual desire from another male character and fulfill the beauty of their sex. These depictions also constitute the aesthetics of erotica distinctive to female sexual expressions, making sexual explicitness in slash unobtrusive and inoffensive - often pleasurable - to both female writers and readers.

But sex with beauty is not enough to attract women; it also has to be enriched by love. "Desire, love, and erotica are inseparable. As long as love is strong, erotica must follow it," said Mandy. Although all the respondents agree that sex is the culmination of love between two male characters in slash, they rarely see slash that contains homoerotic scenes as female porn, which contrasts with Russ' argument that slash is pornography oriented to female readership (1985), because they tend to define pornography as a literary form that only talks about sex - sex without real love - and they gesture towards a categorization of pornography as a male-dominated industry that consumes the female body. These female slash writers have an unsurpassed sensitivity to the issue of women being reduced to sexual objects of male gaze, and they consider slash a genre unique to women's issues - not limited to sexual fantasies, but also concerning love and emotions - that thereby completely differentiates itself from pornography. In short, writing erotica in slash enables these female slashers to act at their own pace and under conditions they choose to develop a female erotica that rivals the male one.

But to normalize erotica is still a difficult task for many women navigating an unfriendly gender culture that often silences female desire as effectively as it silences queer desire. Some female slash writers thus had compromising strategies when they began to write erotica in slash. "I would drink, listen to Latin dance music on Spotify, turn the lights down a bit before writing, and I have to write alone. At first, I could only write after midnight, but later I was able to be more open during the day. I know very well the reason behind this series of preparations - it lies in the sexual shame that has been deeply buried in Chinese women's mindset for thousands of years. My sexual fantasies and fetishes cannot be found out by others; they are something to be ashamed of. So, I have to use some so-called 'force majeure', such as alcohol, to justify my desire... In the beginning of writing slash, I just had no way to overcome it instantly...", said Vickie. But later on, as she wrote, she was able to share those "pornographic plots" with her friends: "In fact, it's not really a big deal!"

Vickie is one of many respondents who began to reflect on the current gender discourses in China as they created more and more slash writings. The lack of sex education, absence of female consciousness, and inertia of patriarchy make them quite dissatisfied with the living environment for women in China. Women's sexual fantasies 


\section{Columbia Undergraduate Research Journal}

remain in a suspended state, because the dominant gender culture in mainland China still regards them as a despicable form of cathartic release. When the social space for expression is denied with the possibility of continuous negation, these fantasies cannot find an embodiment and exist only in the mind. Slash, however, provides an alternative outlet for women's long-suppressed sexual expression, as it has been experienced as an empowering space for women stepping forward to describe their own erotics, and defends the explicit articulation of their female desires. Writing about erotica, about women's erotica, is also a transgressive act to interrogate female sexual repression enforced by the hegemonic gender order.

\section{Writing Within and For a Female Community}

But slashers never write in a vacuum; they are constantly writing within and for a community where production, distribution, and consumption of slash texts are happening at the same time. In the slash community, there is an inherent tension in the circulation of slash materials: slash writers write for those who want to read their writings. That is, the readership often overlaps with the category of people presupposed by the female slash writer, all of whom share the same fan space, making slash consumption an inclusive activity. This inclusiveness, in turn, guarantees the cohesiveness of this female-dominated subcultural community. Attachments, especially emotional, have been formed in reader/reader, writer/writer and reader/writer relationships, propelling the circuits of slash texts within this bounded community.

This unique mode of social interactions in the slash community becomes the root of female slash writers gaining continued motivations and enthusiasm to write for free. A stable readership ensures that there is an audience for every piece of slash, and there is a well-protected space for ongoing discussions about a particular slash text. Many interviewees mentioned that "getting appreciative, fruitful, and encouraging comments" boosted their confidence in both writing more slash pieces and in dealing with daily activities. Angela takes every comment and kudos as a compliment to her writing, saying "I am by nature a very pessimistic person... and dislike of others is normalized in myself - there's nothing about me that's worth their liking all the time. But it's a misconception I'm already trying to change, thanks to everyone's support in this warm community." Some also indicated that their offline friend circle gets expanded because virtual friends they came across in the slash community eventually became real friends in their lives. Thus, writing slash is beyond finishing a slash text itself; post-writing activities matter as well because the experiences gained from virtual interactions between a reader and a writer may extend to the living reality and become slightly relevant to the life of each person in this community.

The significance of post-writing activities for female slash writers also lies in the quick spread of slash texts which can also be a voicing channel. In slash, an author - however marginal in real life - has an opportunity to influence at least some people 


\section{Columbia Undergraduate Research Journal}

by incorporating her system of values into writing and transmitting that to a larger public. A writer's contemplation, confusion, orientations, and thinking habits will be shown in her work, which may not be directly expressed by lines of a character but by her aesthetic choices and value judgements. Contrary to Cicioni's argument (1998) that female slash writers tend to avoid addressing contemporary gender politics in slash texts, many of the interviewees are inclined to declare their political orientations somewhere in their writings, or even through the act of writing itself - writing about subjects that lack a public context of expression in mainland China such as homosexuality, the fundamental component of slash itself. In depicting a virtual world where two men in love can get the same blessing as a man and a woman in love, these slash writers are also upsetting the harsh reality which regulates secondary groups and normalizes their voicelessness. This is a moment when slash blurs boundaries between the personal and political, in which female slash writers voice their political commitments in a fearless whisper. Writing slash offers a platform for political utterances, which may not be pertinent to the life of an individual writer but sustain a participatory culture of minority narratives.

Therefore, quoting Promise's response, 'I am no longer 'me' to some extent, because my story will affect and comfort at least some people, and may even save one or two people who read my texts." Vickie also knew this feeling very well: "Working on slash was initially a kind of self-help for me, but I later discovered that it was also an outstretched hand, drawing some light, wiping away some tears, pulling on a corner of one's coat on a bridge, on a rooftop, and in the waves." Here, boundaries between individual and collective experiences have been blurred, and slash writing has become an outreaching gesture that bundles the virtual and the real.

\section{Conclusion}

This present study explores an important dimension of slash, focusing on how writing slash connects to its socio-cultural surroundings. It reinterprets slash fanfiction by adding an empirically investigated perspective of its producers, the female slash writers, and reconsiders the ways in which slash can serve as a subversive gesture within contemporary gender politics. It is also a region-specific study as it rebuilds narratives around slash in mainland China, a unique social setting nevertheless underrepresented in current slash studies. Future research on slash could more closely engage with the sub-themes of this study, such as how interpersonal emotion is rendered, how homoeroticism is achieved in slash texts, and how these experiences reveal underlying meanings for slash authors and, more broadly, for women. Comparative studies of slash production using content analysis might also be a promising approach in considering slash as a socio-cultural phenomenon in different settings. 


\section{Columbia Undergraduate Research Journal}

Above all, these questions should stick to the issue of the structural position and social context of slash writers and consumers. In slash, women carve out an inclusive space to overtly express things that are still unsayable and unhearable in hegemonic gender discourses, constantly crossing and blurring boundaries between individual and communal lives. Writing slash is an endeavor which may begin without a political agenda, but ultimately interrogates gender normativity in both explicit and implicit ways. Female slash writers gain a sense of empowerment and agency in the way they handle emotions as they rewrite male characters, develop a feminine erotica as they normalize erotica in their writing experiences and strategies, engage in postwriting activities by bundling together virtual and real worlds, and continue to resist and reconceptualize popular notions of sex, sexuality, pornography, and love.

\section{WORKS CITED}

Boyd, K. (2001) One index finger on the mouse scroll bar and the other on my clit: Slash writers' views on pornography, censorship, feminism and risk. [M.A., Simon Fraser University].

Busse, K., \& Hellekson, K. (2006). Work in Progress. pp.5-32. Fan fiction and Fan Communities in the Age of the Internet: New Essays. (edited by Busse, K., \& Hellekson, K., 2006). North Carolina: McFarland.

Cicioni, M. (1998). Male Pair-Bonds and Female Desire in Fan Slash Writing. pp.153177. Theorizing Fandom: Fans, Subculture and Identity. (edited by Harris, C., \& Alexander, A. 1998). Cresskill: Hampton Press.

Cumberland, S. (2003). Private Uses of Cyberspace: Women, Desire, and Fan Culture. pp. 261-279. Retbinking Media Change: The Aesthetics of Transition. (edited by Thornburn, D., \& Jenkins, H., 2003). Massachusetts: The MIT Press.

Faires, Taylor. The Girl, The Myth, The Fanfiction. July 2020. https: / / taylorfaires.com/scalar/the-girl-the-myth-the-fanfiction/index.

Gao, H. (2020). An Experimental Field of Intimacy: The "Female Oriented" Cyberspace and Cultural Production. Theory and Criticism of Literature and Art. 2020(3): 127-139.

Heiden, K. (2016). The value of fanfiction: Female empowerment, identity building, and resistance [M.A., Gonzaga University].

Jenkins, H. (1992). Textual poachers: television fans and participatory culture. New York: Routledge, 2013.

Jones, S. (2002). The Sex Lives of Cult Television Characters. pp. 116-130. The Fan Fiction Studies Reader. (edited by Hellekson, K., \& Busse, K., 2014). Iowa City: University of Iowa Press. 


\section{Columbia Undergraduate Research Journal}

Jung, S. (2004). Queering Popular Culture: Female Spectators and the Appeal of Writing Slash Fan Fiction. Gender Queeries, 2002(2): 30-49.

Kalinowski, P. (2013). The Fairest of Them All: The Creative Interests of Female Fan Fiction Writers and the Fair Use Doctrine Note. William \& Mary Journal of Women and the Law, 20(3), 655-684.

Lamb, P., \& Veith, D. (1986). Romantic Myth, Transcendence, and Star Trek Zines. pp. 97-115. The Fan Fiction Studies Reader. (edited by Hellekson, K., \& Busse, K., 2014). Iowa City: University of Iowa Press.

Lupton, D. (editor) (2020). Doing fieldwork in a pandemic (crowd-sourced document). https://docs.google.com/document/d/1clGjGABB2h2q bduTgfqribHmog B6P0NvMgVuiHZCl8/edit?ts=5e88ae0a\#

Pan, Y. (2020). Slash Fiction: Breaking Boundaries of Gender Identification Through Textual Media. Aesthetics and Literature, 2020(1): 89-91.

Radway, J. (1984). Reading the Romance: Women, Patriarchy, and Popular Literature. Chapel Hill: The University of North Carolina Press, 1984.

Russ, J. (1985). Pornography by Women for Women, with Love. pp. 82-96. The Fan Fiction Studies Reader. (edited by Hellekson, K., \& Busse, K., 2014). Iowa City: University of Iowa Press.

Snitow, A. (1983). Mass Market Romance: Pornography for Women Is Different. pp. 245-262. Powers of Desire: The Politics of Sexuality (ed. By Snitow, A., Stansell, C., \& Tompson, S., 1983). New York: Monthly Review Press.

Zheng, D. (2009). Women's Demands Behind Slash: An Investigation on Slash Texts and Female Fans. Zhejiang Academic Journal, 2009(6): 214-219. 